\title{
Silicon-Germanium Dioxide and Aluminum Indium Gallium Arsenide-Based Acoustic Optic Modulators
}

https://doi.org/10.1515/eng-2020-0065

Received Apr 04, 2020; accepted May 11, 2020

Abstract: The purpose of this study was to clarify the silicon-germanium dioxide $\left(\mathrm{SiGeO}_{2}\right)$ and Aluminum Indium Gallium Arsenide (AlInGaAs) based acoustic optic modulators for upgrading transmission performance characteristics. The transient time response of these modulators is analyzed and discussed in detail. The 3-dB modulation signal bandwidth, diffraction signal efficiency, signal rise time, and signal quality factor with minimum data error rates are also considered. The proposed models with silicon-germanium dioxide and Aluminum Indium Gallium Arsenide acoustic optic modulators were compared to the previous model with silicon acoustic optic modulators. The results confirmed the high-performance efficiency of the proposed models when compared to the previous model, in both the lowest transient time response and the highest acoustic optic modulators speed response.

Keywords: Modulation bandwidth, Acoustic modulators, silicon-germanium dioxide, and Aluminum Indium Gallium Arsenide

\section{Introduction}

Acoustic, optical devices are used in optical systems for light beam control and signal processing applications [14]. Acoustic optics has developed into a mature technology and is deployed in a wide range of optical system applications [5-9]. They are used in optical informa-

\footnotetext{
^Corresponding Author: Ahmed Nabih Zaki Rashed: Electronics and Electrical Communications Engineering Department, Faculty of Electronic Engineering, Menouf 32951, Menoufia University, Egypt; Email: ahmed_733@yahoo.com

Hazem M. El-Hageen: Electrical Engineering Department, Faculty of Engineering, University of Tabuk, Tabuk, Saudi Arabia; Egyptian Nuclear \& Radiological Regulatory Authority, Cairo, Egypt Aadel M. Alatwi: Electrical Engineering Department, Faculty of Engineering, University of Tabuk, Tabuk, Saudi Arabia
}

tion processing, tunable optical filters, deflectors, broadband delay lines, mode-lockers, acoustic optic sensors, and laser radiation modulators [10-13]. An acousto-optic modulator (AOM), also called a Bragg cell, uses sound waves to diffract the frequency of light. As with a permanent Bragg grating, the various wavelengths are spatially diffracted and separated from each other. When ultrasonic waves propagate on optical fibers, it causes periodic microbending of the optical fibers and a change in the refraction index of the fiber core. This bending is called the elasticoptic or acousto-optic effect. Although this basic theory of acousto-optic diffraction in isotropic media was well understood, there were relatively few practical applications before the invention of the laser [14-18]. It was the need for optical devices for laser beam control that stimulated extensive research on the theory and practice of acoustooptics. Over the years, the acousto-optic effect has been exploited for the development of dynamic and reconfigurable all-fiber devices. The use of flexural, longitudinal, or torsional elastic modes led to the development of tunable filters, frequency shifters, and switches [19]. Recently, the acousto-optic effect has also been used as a technique for the fine characterization of optical fibers [20-22], and the generation of cylindrical vector beams $[23,24]$. In recent years, the development of superior acousto-optic materials and efficient broadband transducers are the primary contributors to significant progress in acousto-optic (AO) devices [25, 26].

Modulating an incoming laser light can be achieved with an AOM by varying the amplitude and frequency of acoustic waves traveling through the crystal [27]. Many characteristics, such as laser beam deflection, intensity modulation, phase modulation, and frequency shifting, can all be achieved using the AOM [27]. To describe this acousto-optic effect in crystals, a plane wave analysis can be used to determine the frequency and angular characteristics of the acousto-optic interaction [28-31]. In this approach, the acoustic wave is approximated as a single plane wave typically propagating to the transducer $[17,18$, 32-35]. The frequency or angular dependence is obtained

əopen Access. (c) 2020 H. M. El-Hageen et al., published by De Gruyter. (Cc) BY tion 4.0 License 
from the phase mismatch caused by the change of acoustic frequency or incident optical wave direction [36-43].

\section{Acoustic Optic Modulators Description with Equations Analysis}

Figure 1 shows a basic schematic view of the acoustic optic modulators. The incident optical beam is assumed to be a plane wave propagating near the $z$-axis in the $x z$ plane (referred to as the interaction plane).

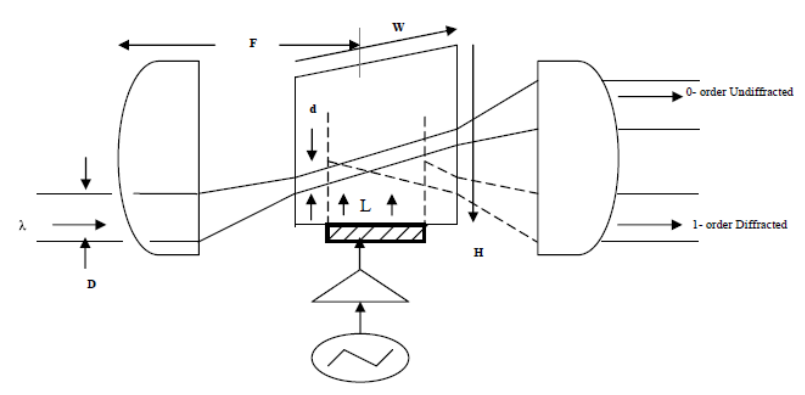

Figure 1: View of the acoustic optic modulators.

To accommodate the finite size of the transducer, the acoustic beam is modeled as an angular spectrum of plane waves propagating near the $\mathrm{x}$-axis. The AO diffraction only occurs in the interaction plane where the phase-matching condition is satisfied. The intensity and distribution of the diffracted light are proportional to the acoustic power spectra. The angle of diffraction is a function of the acoustic frequency, and acoustic velocity of the optical device is $[14,17,18]$ :

$$
\theta=\frac{\lambda f_{a}}{V_{a}},
$$

$\theta$ is the incident beam laser and the diffracted laser beam. The diffraction efficiency is $[14,17,28,37,38]$ :

$$
\eta=\frac{\pi}{\lambda} \sqrt{\frac{M_{2} P_{a} W}{2 H}}
$$

Where $P_{a}$ is the acousto power, $M_{2}$ is the figure of merit for the acoustic optic material, $W$ is the modulator width, $H$ is the modulator length or height. The light beam waist diameter is expressed by [5, 14, 17, 29, 39]:

$$
d=\frac{1.27 F \lambda}{D}
$$

Where $F$ is the length of the focal lens, $D$ is the beam diameter of the laser, and $\left(\tau_{r}\right)$ is the acoustic optic modulator rise time $[5,14,17,40]$ :

$$
\tau_{r}=\frac{0.66 d}{V_{a}},
$$

The 3- $\mathrm{dB}$ frequency bandwidth is a function of the acoustic optic modulator rise time $[5,6,14,17,30,31,41]$ :

$$
f_{3-d B}=\frac{1}{2 \tau_{r}},
$$

The signal modulation frequency of the acoustic optic modulators can be utilized as $[5,6,14,17,32,42]$ :

$$
f_{m}=\frac{0.29 \sqrt{\alpha}}{\tau_{r}},
$$

Where $\alpha$ is the signal loss through the acoustic optic modulators. The modulator transfer function of the acoustic optic modulators can be modeled as the following $[5,6,17$, 33, 43]:

$$
M T F=\exp \left(\left(\frac{0.833 f_{c}}{f_{m}}\right)^{2}\right),
$$

Where the $\mathrm{SiGeO}_{2}$ acoustic optic modulator's acoustic velocity value is $4.2 \times 10^{6} \mathrm{~mm} / \mathrm{sec}$, its loss value is 0.063 $\mathrm{dB} / \mathrm{GHz} . \mathrm{mm}$, and its figure of merit value is $34.5 \times 10^{-15}$ $\mathrm{m}^{2} / \mathrm{W}$. While the AlInGaAs acoustic optic modulators velocity value is $6.32 \times 10^{6} \mathrm{~mm} / \mathrm{sec}$, its loss value is 0.038 $\mathrm{dB} / \mathrm{GHz} . \mathrm{mm}$, and its figure of merit value is $44.8 \times 10^{-15}$ $\mathrm{m}^{2} / \mathrm{W}$. The contrast ratio is a function of both the transfer function and signal modulation frequency and is shown as $[6,14,17,34,35]$ :

$$
\begin{aligned}
& C R\left(f_{m}\right)=\frac{1+M T F\left(f_{m}\right)}{1-M T F\left(f_{m}\right)}, \\
& C R_{d B}=10 \log C R\left(f_{m}\right)
\end{aligned}
$$

Where the materials-based acoustic optic modulators can be expressed as the refractive index $[6,14,17,35]$ :

$$
n=\sqrt{B_{1}+\frac{B_{2} \lambda^{2}}{\lambda^{2}-B_{3}^{2}}}
$$

Where the constants for the proposed $\mathrm{SiGeO}_{2}$ and AlInGaAs AOMs are clarified based on Refs. [6, 7, 14, 17]. Where $\mathrm{B}_{1}=0.6542, \mathrm{~B}_{2}=6.654\left(\mathrm{~T} / \mathrm{T}_{0}\right), \mathrm{B}_{3}=7.8765$ for $\mathrm{SiGeO}_{2} \mathrm{AOM}$, $\mathrm{B}_{1}=1.6543, \mathrm{~B}_{2}=0.2136\left(\mathrm{~T} / \mathrm{T}_{0}\right)$, and $\mathrm{B}_{3}=3.6532$ for AlInGaAs AOM $[6,7,14,17]$. The acoustic optic modulator Q-factor and its bit error rates are expressed as $[5,6,14,17]$ :

$$
Q=\frac{2 \pi \lambda L}{n V_{a}}
$$

The higher the modulation speed, the smaller the transit time that can be achieved. So, the transient AOM time and the modulation speed are expressed as $[14,17,36,43]$ :

$$
\begin{gathered}
T_{t}=\frac{d}{V_{a}}, \\
M S=\frac{0.25}{T_{t}}
\end{gathered}
$$




\section{Simulation Results and Discussions}

The selection of AO materials depends on the specific device application. AlInGaAs is perhaps the best choice for making wideband AO modulators. High optical transparency over the wavelength range of interest is achievable in large single crystals properties that are specifically required for AO device applications. The transient time, modulator Q-factor, modulation contrast ratio, 3-dB frequency bandwidth, modulation frequency, and modulator performance are dependent on the variables defined in Table 1.

Table 1: Variables for the acoustic optic modulators

\begin{tabular}{lll}
\hline Variables & Variable Definition & Values/units \\
\hline $\mathrm{T}=\mathrm{T}_{0}$ & Ambient temperature & $300 \mathrm{~K}-450 \mathrm{~K}$ \\
$\Lambda$ & Laser wavelength & $1550 \mathrm{~nm}$ \\
$\mathrm{f}_{a}$ & Acoustic frequency & $5 \mathrm{KHz}$ \\
$\mathrm{F}$ & Modulator focal length & $10 \mathrm{~mm}$ \\
$\mathrm{D}$ & diameter of laser beam & $0.1 \mathrm{~mm}-0.5 \mathrm{~mm}$ \\
$\mathrm{P}_{a}$ & Acoustic power & $100 \mathrm{~mW}$ \\
$\mathrm{H}$ & Height of modulator & $\mathrm{H}=10 \mathrm{~mm}$ \\
$\mathrm{~L}$ & Length of interaction & $0.35 \mathrm{~mm}$ \\
$\mathrm{~W}$ & Width of the modulator & $8 \mathrm{~mm}$
\end{tabular}

Figure 2 illustrates the variations in modulator rise time related to laser beam diameter for both previous and proposed AOMs at room temperature. The modulator rise time for AlInGaAs AOM is $12 \mathrm{~ns}$ with a $0.1 \mathrm{~mm}$ beam diameter, $9 \mathrm{~ns}$ with a $0.3 \mathrm{~mm}$ beam diameter, and $6 \mathrm{~ns}$ with a $0.5 \mathrm{~mm}$ beam diameter. The modulator rise time for $\mathrm{SiGeO}_{2}$ AOM is $15 \mathrm{~ns}$ with a $0.1 \mathrm{~mm}$ beam diameter, $10.5 \mathrm{~ns}$ with a $0.3 \mathrm{~mm}$ diameter beam, and $6.565 \mathrm{~ns}$ with a $0.5 \mathrm{~mm}$ diame-

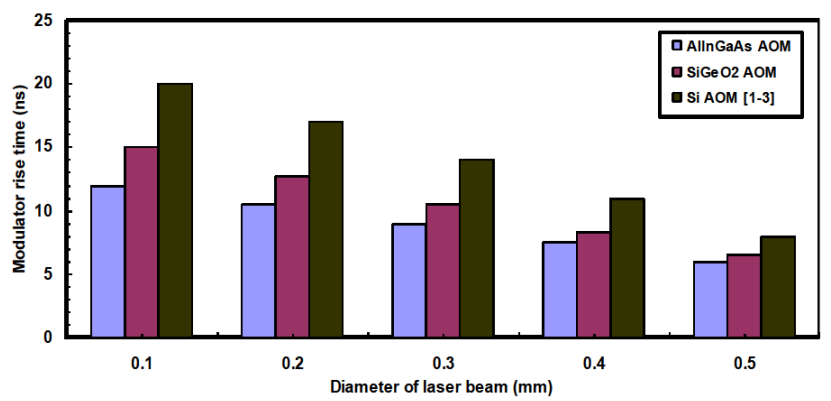

Figure 2: Variations in modulator rise time in relation to laser beam diameter for the previous and the proposed AOMs at room temperature ter beam. For the previous silicon AOM, the modulator rise time is $20 \mathrm{~ns}$ with a $0.1 \mathrm{~mm}$ beam diameter, $14 \mathrm{~ns}$ with a 0.3 $\mathrm{mm}$ beam diameter, and $8 \mathrm{~ns}$ with a $0.5 \mathrm{~mm}$ beam diameter.

Figure 3 shows the variations in modulator frequency response related to beam diameter for both the previous and proposed AOMs at room temperature. The modulator frequency response for AlInGaAs AOM is $3 \mathrm{GHz}$ with a 0.1 $\mathrm{mm}$ beam diameter, $9.81 \mathrm{GHz}$ with a $0.3 \mathrm{~mm}$ beam diameter, and $36 \mathrm{GHz}$ with a $0.5 \mathrm{~mm}$ beam diameter. The modulator frequency response for $\mathrm{SiGeO}_{2} \mathrm{AOM}$ is $2 \mathrm{GHz}$ with a beam diameter of $0.1 \mathrm{~mm}, 8 \mathrm{GHz}$ with a $0.3 \mathrm{~mm}$ beam diameter, and $32 \mathrm{GHz}$ with a $0.5 \mathrm{~mm}$ beam diameter. The modulator frequency response for the previous silicon AOM is $1.5 \mathrm{GHz}$ with a $0.1 \mathrm{~mm}$ beam diameter, $6 \mathrm{GHz}$ with a $0.3 \mathrm{~mm}$ beam diameter, and $24 \mathrm{GHz}$ with a $0.5 \mathrm{~mm}$ beam diameter.

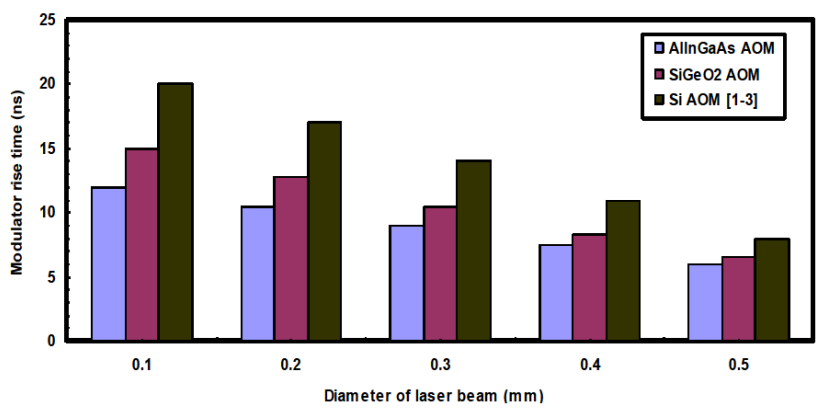

Figure 3: Variations in modulator frequency response in relation to laser beam diameter for the previous and the proposed AOMs at room temperature

Figure 4 shows the variations in modulation frequency in relation to the laser beam diameter for both the previous and proposed AOMs at room temperature. The modulation frequency for AlInGaAs AOM is $6 \mathrm{GHz}$ with a 0.1 $\mathrm{mm}$ beam diameter, $24 \mathrm{GHz}$ with a $0.3 \mathrm{~mm}$ beam diame-

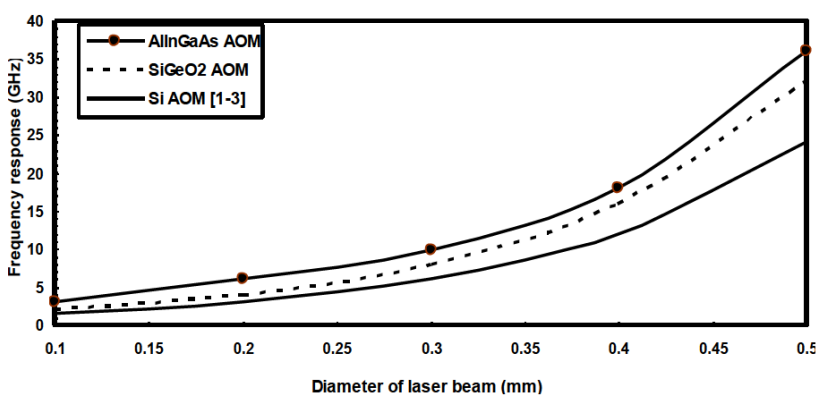

Figure 4: Variations in modulation frequency in relation to laser beam diameter for the previous and proposed AOMs at room temperature 
ter, and $96 \mathrm{GHz}$ with a $0.5 \mathrm{~mm}$ beam diameter. The modulation frequency for $\mathrm{SiGeO}_{2} \mathrm{AOM}$ is $5 \mathrm{GHz}$ with a $0.1 \mathrm{~mm}$ beam diameter, $20 \mathrm{GHz}$ with a $0.3 \mathrm{~mm}$ beam diameter, and $80 \mathrm{GHz}$ with a $0.5 \mathrm{~mm}$ beam diameter. The modulation frequency for the previous silicon AOM is $4 \mathrm{GHz}$ with a $0.1 \mathrm{~mm}$ beam diameter, $16 \mathrm{GHz}$ with a $0.3 \mathrm{~mm}$ beam diameter, and $64 \mathrm{GHz}$ with a $0.5 \mathrm{~mm}$ beam diameter.

Figure 5 shows the variations in modulator speed response in relation to the laser beam diameter for both the previous and proposed AOMs at room temperature. The modulator speed response for AlInGaAs AOM is $6.5 \mathrm{GHz}$ with a $0.1 \mathrm{~mm}$ beam diameter, $25 \mathrm{GHz}$ with a $0.3 \mathrm{~mm}$ beam diameter, and $97 \mathrm{GHz}$ with a $0.5 \mathrm{~mm}$ beam diameter. The modulator speed response for $\mathrm{SiGeO}_{2} \mathrm{AOM}$ is $5.5 \mathrm{GHz}$ with a $0.1 \mathrm{~mm}$ beam diameter, $21 \mathrm{GHz}$ with a $0.3 \mathrm{~mm}$ beam diameter, and $82 \mathrm{GHz}$ with a $0.5 \mathrm{~mm}$ beam diameter. The modulator speed response for the previous silicon AOM is 4.5 $\mathrm{GHz}$ with a $0.1 \mathrm{~mm}$ beam diameter, $18 \mathrm{GHz}$ with a $0.3 \mathrm{~mm}$ beam diameter, and $66 \mathrm{GHz}$ with a $0.5 \mathrm{~mm}$ beam diameter.

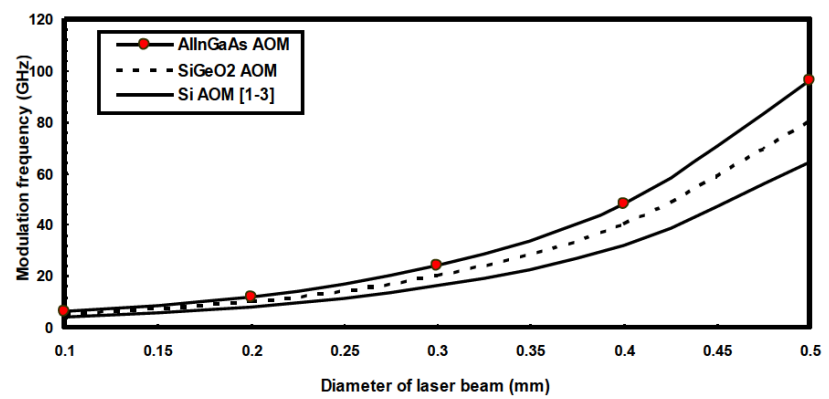

Figure 5: Variations in modulator speed response in relation to laser beam diameter for the previous and proposed AOMs at room temperature

Figure 6 shows the variations in modulator transient time response in relation to the laser beam diameter for the

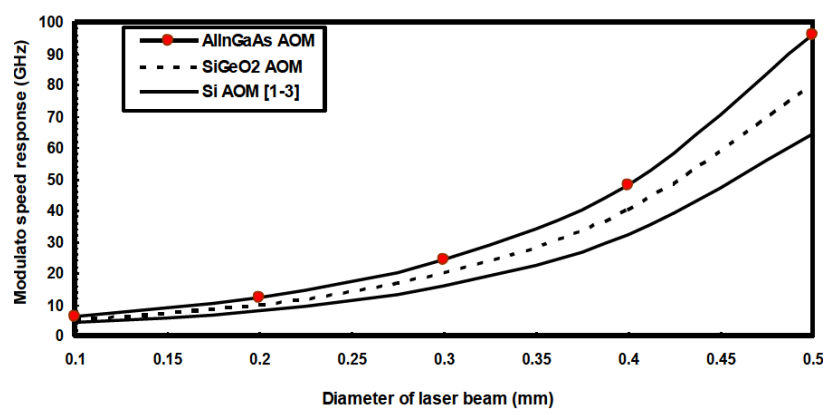

Figure 6: Variations in modulator transient time response in relation to laser beam diameter for the previous and proposed AOMs at room temperature previous and proposed AOMs at room temperature. The modulator transient time response for AlInGaAs AOM is $320 \mathrm{~ns}$ with a $0.1 \mathrm{~mm}$ beam diameter, $200 \mathrm{~ns}$ with a $0.3 \mathrm{~mm}$ beam diameter, and $75 \mathrm{~ns}$ with a $0.5 \mathrm{~mm}$ beam diameter. The modulator transient time response for $\mathrm{SiGeO}_{2} \mathrm{AOM}$ is $350 \mathrm{~ns}$ with a $0.1 \mathrm{~mm}$ beam diameter, $250 \mathrm{~ns}$ with a 0.3 $\mathrm{mm}$ beam diameter, and $120 \mathrm{~ns}$ with a $0.5 \mathrm{~mm}$ beam diameter. The modulator transient time response for the previous silicon AOM is $480 \mathrm{~ns}$ with a $0.1 \mathrm{~mm}$ beam diameter, 400 ns with $0.3 \mathrm{~mm}$ beam diameter, and $275 \mathrm{~ns}$ with a $0.5 \mathrm{~mm}$ beam diameter.

Figure 7 shows the variations in the modulation contrast ratio in relation to the laser beam diameter for the previous and proposed AOMs at room temperature. The modulation contrast ratio for AlInGaAs AOM is $0.3 \mathrm{~dB}$ with a 0.1 $\mathrm{mm}$ beam diameter, $1.2 \mathrm{~dB}$ with a $0.3 \mathrm{~mm}$ beam diameter, and $4.8 \mathrm{~dB}$ with a $0.5 \mathrm{~mm}$ beam diameter. The modulation contrast ratio for $\mathrm{SiGeO}_{2} \mathrm{AOM}$ is $0.2 \mathrm{~dB}$ with a $0.1 \mathrm{~mm}$ beam diameter, $0.8 \mathrm{~dB}$ with a $0.3 \mathrm{~mm}$ beam diameter, and $3.2 \mathrm{~dB}$ with a $0.5 \mathrm{~mm}$ beam diameter. The modulation contrast ratio for the previous silicon AOM is $0.1 \mathrm{~dB}$ with a $0.1 \mathrm{~mm}$ beam diameter, $0.4 \mathrm{~dB}$ with a $0.3 \mathrm{~mm}$ beam diameter, and $1.6 \mathrm{~dB}$ with a $0.5 \mathrm{~mm}$ beam diameter.

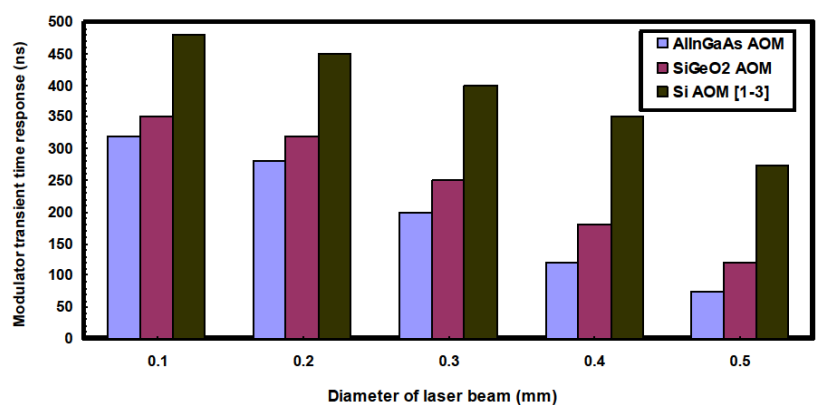

Figure 7: Variations in modulation contrast ratio in relation to laser beam diameter for the previous and proposed AOMs at room temperature

Figure 8 illustrates the variation in the signal Q Factor in relation to ambient temperature for the previous and proposed AOMs. The Q Factor for AlInGaAs AOM is 15 at room temperature, 8.5 at $375 \mathrm{~K}$, and 3.65 at $450 \mathrm{~K}$. The $\mathrm{Q}$ Factor for $\mathrm{SiGeO}_{2} \mathrm{AOM}$ is 12 at room temperature, 8 at 375 $\mathrm{K}$, and 3 at $450 \mathrm{~K}$. The Q Factor for the previous silicon $\mathrm{AOM}$ is 10 at room temperature, 7 at $375 \mathrm{~K}$, and 2 at $450 \mathrm{~K}$. 


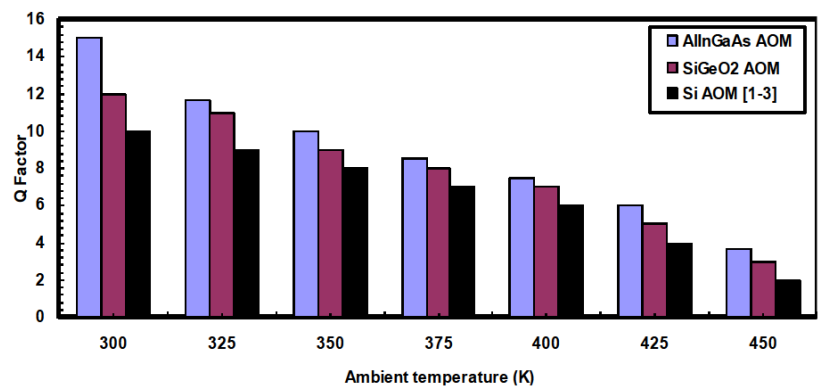

Figure 8: Variations in Q Factor in relation to ambient temperature for the previous and proposed AOMs

\section{Conclusion}

We have studied the different AlInGaAs and $\mathrm{SiGeO}_{2}$ acousto optic modulators for upgrading fiber optic communication systems. AlInGaAs AOM presented the highest $\mathrm{Q}$ factor, modulation contrast ratio, modulation speed response, and the lowest transient time speed response in comparison to the previous silicon AOM. Modulation frequency, frequency response, and rise time were also evaluated. All of the positive results focused on the proposed AOMs under the same ambient temperature and diameter of laser beam variations. Therefore, AlInGaAs is the best choice for upgrading wideband $\mathrm{AO}$ modulators in fiber optic communications.

\section{References}

[1] Lee MC, Wu MC. Tunable coupling regimes of silicon microdisk resonators using MEMS actuators. Opt Express. 2006 May;14(11):4703-12.

[2] Shakin OV, Nefedov VG, Churkin PA. Aplication of Acoustooptics in Electronic Devices. Wave Electronics and its Application in Information and Telecommunication Systems. 2018. https://doi.org/10.1109/WECONF.2018.8604351.

[3] Chen L, Preston K, Manipatruni S, Lipson M. Integrated GHz silicon photonic interconnect with micrometer-scale modulators and detectors. Opt Express. 2009 Aug;17(17):15248-56.

[4] Ferriai K, Laouari N, Bouaouadia N. Acousto-optic method for liquids refractometry. Opt Appl. 2011;41(1):109-19.

[5] Young Y, Yao E. Design Consideration for Acousto-Optic Devices. Proc IEEE. 2005;69(1):54-11.

[6] Johnson RV. Temporal Response of the Acousto Optic Modulator in the High Scattering Eflciency Regime. Applied Optics. 2005; 30 18(3):903-5.

[7] Limpert J, Deguil-Robin N, Manek-Hnninger I, Salin F, Schreiber T, Liem A, Rser F, Zellmer H, Tünnermann A, Courjaoud A, Hnninger C, and Mottay N. High Power Picosecond Fiber Amplifier Based on Nonlinear Spectral Compression. Opt. Lett. 2005;5 30(3):714-3. https://doi.org/10.1364/OL.30.000714.
[8] Datta P, Mukhopadhyay S, Das S, Tartara L, Agnesi A, Degiorgio V. Enhancement of stability and efficiency of a nonlinear mirror mode-locked Nd:YVO(4) oscillator by an active Q-switch. Opt Express. 2004 Aug;12(17):4041-6.

[9] Rashed AN. High Performance Photonic Devices For Multiplexing/Demultiplexing applications in Multi Band Operating Regions. J Comput Theor Nanosci. 2012;9(4):522-9.

[10] Zhang X, Song Z, Yu Y, Chen Y, Sun S, Meng Z. Optical Fiber Acoustic Sensor with an All-optical Phase Modulator based on Special Optical Microfiber. International Conference on Optical Mems and Nanophotonics. 2016.

[11] Nikitenko AN, Volkovskiy SA, Mikheev MV, Aleynik AS, Kikilich NE. Influence of Acousto-Optic Resonances in ElectroOptical Modulator on Fiber Optic Gyro Performance and Method for Its Compensation. IEEE Sens J. 2018;18(1):1-7.

[12] Liu H, Zhang W, Meng L, Yang A, Zeng X. All-fiber Mode Acoustooptic Modulator in Gas Absorption Measurement. $18^{\text {th }}$ International Conference on Optical Communications and Networks. 2018.

[13] Qian H, Shao LY, Zhang W, Zhang X, He H, Zou X. Viscosity Measurement Based on Acousto-Optic Effect on Fiber Bragg Grating. Asia Communications and Photonics Conference (ACP). 2017. https://doi.org/10.1364/ACPC.2017.Su2A.88.

[14] Garca G, Flores E, Pntle JA, Italo C, Ernest C. Acoustic Detector all Fiber Optics Using Sagnac Interferometer as modulator of Index Changes of Fiber High Birefringence. Canadian Journal on Electrical and Electronics Engineering. 2011;2(1):8-13.

[15] Rashed AN. Development of Optical Interconnections Modules System Architectures and Its Backplane Technology for Terabit Systems [IJARCSEE]. International Journal of Advanced Research in Computer Science and Electronics Engineering. 2012;1(8):717.

[16] Goodman JW. Linear Space Variant Optical Data Processing in Optical Information Processing Fundamentals. Appl Phys (Berl). 2002;48(3):1324-35.

[17] Mayden D. Acousto Optical Pulse Modulators. Journal of Quantum Electronics. 2005;6(1):15-9.

[18] Amiri IS, Rashed AN. Numerical investigation of V shaped three elements resonator for optical closed loop system. Indonesian Journal of Electrical Engineering and Computer Science. 2019;16(3):1392-6.

[19] Alcusa-Sez EP, Dez A, Pérez ER, Margulis W, Norin L, Andrés MV. All-fiber acousto-optic tunable filter in polyimide coated optical fibers. $19^{\text {th }}$ International Conference on Transparent Optical Networks (ICTON). 2017. https://doi.org/10.1109/ICT ON.2017.8025093.

[20] Alcusa-Sez EP, Dez A, Gonzlez-Herrez M, Andrés MV. Timeresolved acousto-optic interaction in single-mode optical fibers: characterization of axial non uniformities at the nanometer scale. Opt Lett. 2013;39(6):1437-8.

[21] Alcusa-Sáez EP, Díez A, González-Herráez M, Andrés MV. Improved time-resolved acousto-optic technique for optical fiber analysis of axial non-uniformities by using edge interrogation. Opt Express. 2015 Mar;23(6):7345-50.

[22] Alcusa-Sáez E, Díez A, Andrés MV. Accurate mode characterization of two-mode optical fibers by in-fiber acousto-optics. Opt Express. 2016 Mar;24(5):4899-905.

[23] Zhang W, Huang L, Wei K, Li P, Jiang B, Mao D, et al. Cylindrical vector beam generation in fiber with mode selectivity and wavelength tunability over broadband by acoustic flexural wave. Opt Express. 2016 May;24(10):10376-84. 
[24] Carrin-Higueras L, Alcusa-Sez EP, Dez A, Andrés MV. All-fiber laser with intracavity acousto-optic dynamic mode converter. IEEE Photonics J. 2017;9(1):33-6.

[25] Andrushchak AS, Mytsyk BG, Demyanyshyn NM, Kaidan MV, Yurkevych OV. Design of optimization technique for electro- and acousto-optical interactions of light in crystalline materials. $9^{\text {th }}$ International Conference on Laser and Fiber-Optical Networks Modeling. 2008. https://doi.org/10.1109/LFNM.2008.4670341.

[26] Andrushchak A, Buryy 0. The Optimal Geometry of the Acousto Optic Interaction in Selected Crystalline Materials Determined by Extreme Surfaces Method. $8^{\text {th }}$ IEEE International Conference on Advanced Optoelectronics and Lasers (CAOL). 2019. https://doi.org/10.1109/CAOL46282.2019.9019517.

[27] Mesleh R. AL-Olaimat A. Acousto-Optical Modulators for Free Space Optical Wireless Communication Systems. J. Opt. Commun. 2018;10(5):1-8.

[28] Jun Kim H, Song J. Full-Duplex WDM Based ROF System Using AllOptical SSB Frequency Up Conversion and Wavelength Re-Use Techniques. IEEE Trans Microw Theory Tech. 2010;49(2):1354-9.

[29] Chen M, Zhou L, Hara T, Xiao Y, Leung VC. Advances in Multi media Communications. Int J Commun Syst. 2011;24(10):1243-3.

[30] Genack AZ. Phase Sensitive Detection of Emission and Scattering by Electro Optic Demodulation. J Lumin. 2011;32(2):696-3.

[31] Yao X, Maleki L. Optoelectronic oscillators for photonic systems. J. of Quantum Electronics. 1996;32(7):1142-8.

[32] Rashed AN, Tabbour MS. Suitable Optical Fiber Communication Channel for Optical Nonlinearity Signal Processing in High Optical Data Rate Systems. Wireless Personal Communications Journal. 2017;97(1):397-20.

[33] Rashed AN, Tabour MS, El-Meadawy S. Optimum Flat Gain With Optical Amplification Technique Based on Both Gain Flattening Filters and Fiber Bragg Grating Methods. Journal of Nanoelectronics and Optoelectronics. 2018;13(5):665-13.

[34] Rashed AN, Tabbour MS. The Trade Off Between Different Modulation Schemes for Maximum Long Reach High Data Transmission Capacity Optical Orthogonal Frequency Division Multiplexing (OOFDM). Wireless Personal Communications Journal. 2018;101(1):325-13.

[35] Rashed AN, Mohammed A, Zaky WF, Amiri IS, Yupapin P. The switching of optoelectronics to full optical computing operations based on nonlinear metamaterials. Results Phys. 2019;13:102152.
[36] Amiri IS, Houssien FM, Rashed AN, Mohammed AA. Temperature effects on characteristics and performance of near-infrared wide bandwidth for different avalanche photodiodes structures. Results Phys. 2019;14:102399.

[37] Amiri IS, Rashed ANZ, Yupapin P. Mathematical Model Analysis of Dispersion and Loss in Photonic Crystal Fibers. Journal of Optical Communications. Published online: April 2019. https://doi.org/10.1515/joc-2019-0052.

[38] Amiri IS, Rashed ANZ, Yupapin P. Basic Functions of Fiber Bragg Grating Effects on the Optical Fiber Systems Performance Efficiency. Journal of Optical Communications. Published Online: 5 April 2019. https://doi.org/10.1515/joc-2019-0042.

[39] Amiri IS, Rashed ANZ, Mohammed AA, Aboelazm MB, Yupapin P. Nonlinear Effects with Semiconductor Optical Amplifiers. Journal of Optical Communications. Published Online: 12 April 2019. https://doi.org/10.1515/joc-2019-0053.

[40] Amiri IS, Rashed ANZ, Yupapin P. High-Speed Light Sources in High-Speed Optical Passive Local Area Communication Networks. Journal of Optical Communications. Published Online: 20 April 2019. https://doi.org/10.1515/joc-2019-0070.

[41] Amiri IS, Rashed ANZ, Mohammed AA, El-Din ES, Yupapin P. Spatial Continuous Wave Laser and Spatiotemporal VCSEL for High Speed Long Haul Optical Wireless Communication Channels. Journal of Optical Communications. Published Online: 24 April 2019. https://doi.org/10.1515/joc-2019-0061.

[42] Amiri IS, Rashed ANZ, Yupapin P. Average Power Model of Optical Raman Amplifiers Based on Frequency Spacing and Amplifier Section Stage Optimization. Journal of Optical Communications. Published Online: 4 May 2019. https://doi.org/10.1515/joc-20190081.

[43] Amiri IS, Rashed ANZ. Power Enhancement of the U-shape Cavity Microring Resonator Through Gap and Material Characterizations. Journal of Optical Communications. Published Online: 19 Oct. 2019. https://doi.org/https://doi.org/10.1515/joc-20190108. 